\title{
Correlations of smoking with cumulative total dust exposure and cumulative abnormal rate of pulmonary function in coal-mine workers
}

\author{
QING-ZENG QIAN $^{1}$, XIANG-KE CAO $^{2}$, FU-HAI SHEN $^{1}$ and QIAN WANG $^{1}$ \\ ${ }^{1}$ Experimental Teaching Demonstration Center, Central Laboratory, College of Public Health; \\ ${ }^{2}$ Central Laboratory, College of Life Sciences, North China University of \\ Science and Technology, Tangshan, Hebei 063000, P.R. China
}

Received April 15, 2015; Accepted May 23, 2016

DOI: $10.3892 /$ etm.2016.3700

\begin{abstract}
The present study aimed to investigate the correlation of smoking with cumulative total dust exposure (CTE) and cumulative abnormal rate of pulmonary function in coal-mine workers. A total of 376 coal-mine workers were recruited as the observational group, while 179 healthy workers in other industries were selected as the control group. All the workers underwent pulmonary function testing to determine their forced vital capacity (FVC), forced expiratory volume in 1 second (FEV1) and FEV1/FVC, in order to compare the abnormal pulmonary function between the two groups. A markedly higher number of smokers was observed in the observational group $(200 / 376,53.19 \%)$ when compared with the control group $(72 / 179,40.22 \%)$. In smokers, the abnormal rate of pulmonary function in the observational group $(102 / 200,51.00 \%)$ was evidently higher compared with that in the control group $(19 / 72,26.39 \%)$, whereas no significant difference was detected between the two groups of non-smokers $(\mathrm{P}=0.077)$. In addition, FVC, FEV1 and FEV1/FVC of the observational group were found to be lower compared with those in the control group, in both the smoking and non-smoking subgroups. In the smoking subgroup, FVC and FEV1 in subjects working at the coal mine for different number of years showed significant differences (all $\mathrm{P}<0.05$ ), whereas comparison of FEV1/FVC in workers with different working durations showed no significant difference $(\mathrm{P}=0.169)$. However, in the non-smoking subgroup, the comparison of FVC, FEV1 and FEV1/FVC in different working duration groups also showed no significant difference
\end{abstract}

Correspondence to: Professor Qing-Zeng Qian, Experimental Teaching Demonstration Center, Central Laboratory, College of Public Health, North China University of Science and Technology, 57 Jianshe South Road, Tangshan, Hebei 063000, P.R. China E-mail: qianqingzeng804@126.com

Key words: coal-mine drillers, smoking, cumulative total dust exposure, cumulative abnormal rate, pulmonary function test, pneumoconiosis (all P>0.05). Furthermore, FVC, FEV1 and FEV1/FVC in smoking coal-mine workers were negatively correlated with the dust-exposure working duration $(\mathrm{P}<0.05)$. CTE was also positively correlated with cumulative abnormal rate of pulmonary function in the smoking and non-smoking subgroups, while FEV1 was negatively correlated with CTE in the smoking subgroup $(\mathrm{P}=0.009)$. In conclusion, smoking is an important risk factor for the damage of pulmonary function in coal-mine workers, and it is positively correlated with dust-exposure time and CTE in these individuals.

\section{Introduction}

In recent years, the coal mining industry has been developing at a high speed, which has significantly increased the incidence of occupational disease (1). Coal miners are at a risk for certain lung diseases, including silicosis, coal worker's pneumoconiosis (CWP) and mixed dust pneumoconiosis, along with chronic airway diseases and dust-associated diffuse fibrosis (2). CWP, a progressive and irreversible lung disease occurring worldwide, mainly results from the inhalation and accumulation of respirable coal and silica dusts (3). According to statistics, there were $\sim 24,206$ new cases of CWP diagnosed in 2012, which accounted for $\sim 88.28 \%$ of all reported occupational diseases (4). Similar to other lung diseases, a person's risk of developing CWP results from various factors, such as free silica content, concentration of respirable coal dust, particle size with its composition of coal dust, age, duration of exposure and work environment of workers (5). CWP is reported to greatly influence patients' health, since it can exacerbate other diseases or even result in disability and mortality, but also increases the burdens of the national health care system (6). Currently, not all the active coal miners with CWP have worked under dust standards based on the Federal Coal Mine Health and Safety Act of 1969, implying that workers in the coal mining industry still lack adequate protection from coal mine dust-associated disease (7).

Pulmonary function tests (PFTs) are usually applied to identify and quantify abnormalities and defects in the function of the respiratory system (8). PFTs evaluate the entire respiratory system through physical examinations, investigation of patient history, tests of pulmonary function, arterial blood gas 
analysis, as well as chest X-ray examinations (9). The forced vital capacity (FVC), forced expiratory volume in 1 second (FEV1) and FEV1/FVC are three common measures that clinically relevant to pulmonary function (10). FEV1 and FVC are affected by the size of the lung and are also reduced by restrictive lung diseases, which lead to a greater reduction in FEV1 compared with FVC (11). In addition, reduced FEV1/FVC, independent of lung size and indicative of airflow obstruction, is the main criterion for defining obstructive hypoventilation (12). PFTs have an important guiding significance for the early detection of lung and airway diseases, the assessment of severity and prognosis of disease, and the identification of the reasons for expiratory dyspnea (13).

It is well-known that smoking can lead to the occurrence and development of various diseases, such as cerebrovascular disease, cancer, respiratory system disease and cardiovascular disease (14). A previous study proposed that the combined effect of smoking and dust is an important factor causing a decline in pulmonary function of dust-exposed workers (15). Respirable coal dust concentration in the working area, and cumulative total dust exposure (CTE) is a significant risk factor for abnormal pulmonary function, and a previous study observed that CTE may lead to COPD, including chronic bronchitis and emphysema (2). Therefore, in order to increasing the life span of coal-mine workers, the present study aimed to investigate the correlation of smoking with CTE and cumulative abnormal rate of pulmonary function in 376 coal-mine workers.

\section{Materials and methods}

Ethics statement. The study was performed with the approval of the Institutional Review Board of the Experimental Teaching Demonstration Center, Central Laboratory, College of Public Health of North China University of Science and Technology (Tangshan, China). Informed written consent was collected from each eligible worker and the entire study was performed based on the Declaration of Helsinki (16).

Subjects. A total of 376 male workers specialized in mining operations, who did not change occupation since they began coal mining operations, were selected from a coal mine in Tangshan as the observation group. These male subjects were aged between 21 and 59 years, with a mean age of $40.67 \pm 11.17$ years, body weight of $47-86 \mathrm{~kg}$, mean body weight of $66.47 \pm 11.37 \mathrm{~kg}$, mean height of $170.8 \pm 6.24 \mathrm{~cm}$ and mean working duration of $22.53 \pm 9.56$ years. Workers were considered to be dust-exposed and were included into the study if they met the following criteria: i) Exposure to dust for $>1$ year; ii) exposure time in the specific coal mine accounted for $>50 \%$ of their total exposure time; iii) health examination results within the past 2 years were available; and iv) the history of changes in work were clear and complete, or could be completed through archives.

In addition, 179 healthy male workers in the instrument and meter plant and electrical power plant, which were in the same area as the coal mine, were selected as the control group of non-dust exposure workers. Control subjects were aged between 20 and 58 years, with a mean age of $38.99 \pm 11.62$ years, body weight of $46-87 \mathrm{~kg}$, mean body weight of $66.65 \pm 11.81 \mathrm{~kg}$, and mean height of $169.3 \pm 5.32 \mathrm{~cm}$. There was no statistically significant difference in the age, gender, body weight and height between the two groups $(\mathrm{P}>0.05)$. The selected subjects were free of active tuberculosis, short-term (within 2 weeks) bronchial-pulmonary infection history, bronchial asthma, and heart, liver, kidney, immune system or endocrine system diseases. Furthermore, the subjects had not received treatments affecting the immune and endocrine functions. A professional physician performed unified health inspection using a unified health examination form, which was completed individually for each participant. The main information collected included the following: Name, gender, age, height, body weight, temperature, pressure, smoking status, type of dust exposed to, dust work history, work environment, protection measures and past medical history.

PFT. The determination and analysis of PFT results were performed by respiration physicians using Beijing AS.507 type spirometer (Beijing Kangxin Tongchuang Science and Technology Co. Ltd., Beijing, China). Prior to the examination, the subjects were instructed to rest for 5-10 $\mathrm{min}$ and to breath calmly 4-5 times before each test. The subjects inhaled deeply, aligning the inlet of the equipment with the oral cavity, and subsequently exhaled deeply as fast as possible. The pulmonary function measurement parameters included FVC, FEV1 and FEV1/FVC. The optimum results obtained from three or more measurements in each subject were selected as the final results of the pulmonary function.

Evaluation criteria. Smoking was evaluated based on the smoking index, which was calculated by the number of cigarettes smoked per day per smoking year. Subjects with a smoking index $\geq 20$ were classified as smokers, while subjects with an index $<20$ were classified as non-smokers.

Abnormal pulmonary functions were evaluated according to the relative values of FVC and FEV1, with the exception of FEV1/FVC. The relative value was calculated as follows: (Actual measured value / theoretical value) x $100 \%$. The theoretical value was obtained using a PFT instrument and a computational formula (17) based on the age, gender, height, weight, temperature, pressure and other factors, while the relative value eliminated the influence of the aforementioned factors. Generally, an index with a theoretical value of $\geq 80 \%$ was considered as normal, according to the techniques and methods of compiled normal values of pulmonary function reported nationwide (18).

Dust-exposure time was also evaluated. The dust-exposed working duration was considered to be 1 year in subjects exposed to coal dust for 1 full year, without changes in work history. Subjects were divided into the following four groups, according to the dust-exposure working duration: $<10$ years, 10-20 years, 20-30 years and $>30$ years.

$C T E$. According to the detection data of dust-exposure levels reported between 1970 and 2013 by the Safety and Environmental Protection Department of the coal mine (total dust concentration is mainly measured by the filter membrane method) (19), the work history of subjects was carefully investigated, including details on the work hours or the length of time working in the mine in their career, and any changes in the type of work. The CTE of each coal-mine worker was 
calculated as follows: $\mathrm{CTE}=\sum(\mathrm{Ci} \times \mathrm{Ti})$, where $\mathrm{Ci}$ is the dust concentration the worker was exposed to at a certain period of time, and $\mathrm{Ti}$ is the working year during which the worker was exposed to this concentration. CTE is expressed in terms of $\mathrm{mg} / \mathrm{m}^{3}$.years.

Cumulative abnormal rate of pulmonary function. The cumulative abnormal rate of pulmonary function was calculated as follows: Cumulative abnormal rate $=1$ - cumulative normal rate; cumulative normal rate $=(1-$ abnormal rate $) \times(1-$ higher abnormal rate); abnormal rate $=$ morbidity [number of subjects at the beginning of the period - (number of subjects at the end of the period / 2)]. Number of subjects at the beginning of the period refers to all the individuals with a certain initial CTE, while the number at the end of the period refers to all the individuals with a certain CTE at the end.

Statistical analysis. The calculation formula according to quantitative results of sample size was as follows: $\mathrm{n}=\left[2 \sigma^{2} /\left(\mu_{2}-\mu_{1}\right)^{2}\right] \mathrm{x} \mathrm{f}^{+}(\alpha, \beta)$, and this formula was used to calculate whether the research object met the required sample size. $\mu_{1}$ and $\mu_{2}$ refer to the mean values in non-dust exposed and dust-exposed workers, respectively. $\sigma$ refers to standard deviation, $f(\alpha, \beta)$ refers to the function. $\alpha$ refers to the probability of the first type of error and $\beta$ is the probability of second type of error. Considering the relative value of FEV1 as an example, if $\alpha=0.05, \beta=0.10$ and $\mathrm{f}^{+}(\alpha, \beta)=10.5$, and the results of the present study were $\mu_{1}=87.46, \mu_{2}=79.07$ and $\sigma=14.63$, then the obtained sample size would be 63.85 . Therefore, a sample size of 64 cases is required in this test, while the actual sample size of the control group was 179 cases, and the sample size of the dust-exposed worker group was 376 cases; thus, the sample sizes included in the present study satisfy the required number.

In the current study, the associated information was collected and a database was established. SPSS version 16.0 software (SPSS, Inc., Chicago, IL, USA) was used for data analysis and processing. Measurement data are presented as the mean \pm standard deviation, and were analyzed using $\mathrm{t}$ test and $\mathrm{F}$ test. Enumeration data are presented as \%, and were analyzed using $\chi^{2}$ test. Correlations were analyzed by Pearson's correlation. A P-value of $<0.05$ was considered to indicate a statistically significant difference.

\section{Results}

Distribution of smoking status in the observational and control groups. The distribution of smoking status in the observational and control groups is displayed in Fig. 1. In the observational group, 200/376 subjects (53.19\%) were smokers, which was higher compared with the number of smokers in the control group (72/179 subjects; $40.22 \%)$, with a significant difference observed $\left(\chi^{2}=8.16 ; \mathrm{P}=0.004\right)$.

Comparison of cumulative abnormal rate of pulmonary function in the observational and control groups. As shown in Fig. 2, the cumulative abnormal rate of pulmonary function within smokers in the observational group $(102 / 200$; $51.00 \%$ ) was evidently higher compared with that of smokers in the control group, with a statistically significant difference identified $\left(\chi^{2}=12.98 ; \mathrm{P}=0.003\right)$. However, in the non-smoking

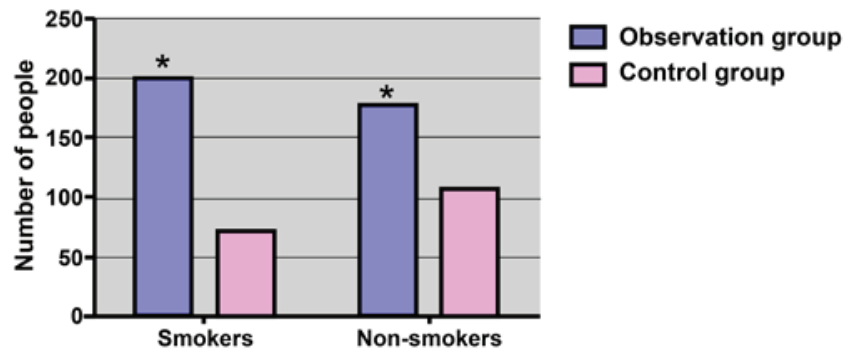

Figure 1. Smoking distribution in the observational and control groups. ${ }^{*} \mathrm{P}<0.05$, vs. the control group.

A

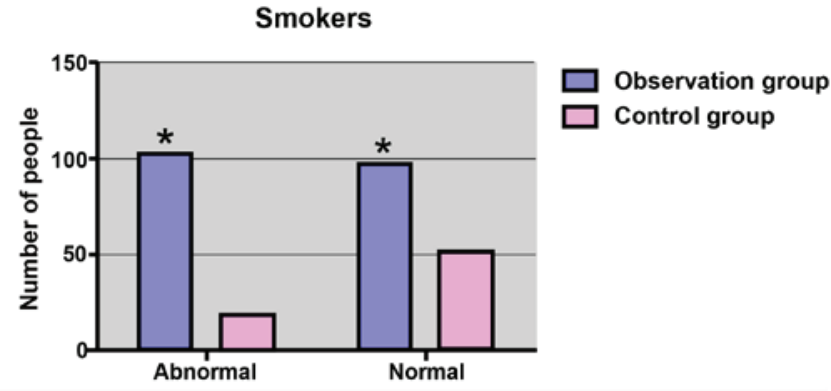

B Non-smokers

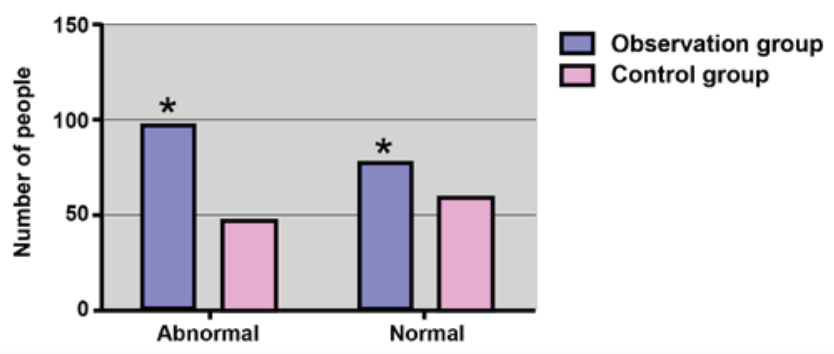

Figure 2. Analysis of the abnormal rate of pulmonary function in (A) smokers and (B) non-smokers. ${ }^{*} \mathrm{P}<0.05$, vs. the control group.

subgroup, the cumulative abnormal rate of pulmonary function in the control group was $44.86 \%(48 / 107)$, while the rate was $55.68 \%(98 / 176)$ in the observational group, with no significant difference observed $\left(\chi^{2}=3.121 ; \mathrm{P}=0.077\right)$.

Comparison of FVC, FEVI and FEVI/FVC values. In the smoking and non-smoking subgroups, FVC and FEV1 in the observational group were markedly lower compared with those in the control group (both $\mathrm{P}<0.05$ ). In addition, FEV1/FVC in the observational group was weakly lower compared with that in the control group; however, no significant difference was detected $(\mathrm{P}>0.05$; Table I).

As shown in Table II, in the smoking subgroup, FVC and FEV1 in the group with a working duration of $>30$ years were evidently lower compared with the values in the $<10$-year, 10-20-year and 20-30-year working duration group (all $\mathrm{P}<0.05)$. Comparison of FEV1/FVC in different working duration groups showed no significant difference $(\mathrm{P}=0.169)$. However, in the non-smoking subgroup, the comparison of FVC, FEV1 and FEV1/FVC in different working duration groups also showed no significant difference (all $\mathrm{P}>0.05$ ). 
Table I. Comparison of FVC, FEV1 and FEV1/FVC between the observational and control groups.

\begin{tabular}{|c|c|c|c|c|c|c|c|c|}
\hline \multirow[b]{2}{*}{ Group } & \multicolumn{4}{|c|}{ Non-smoking subgroup } & \multicolumn{4}{|c|}{ Smoking subgroup } \\
\hline & $\mathrm{n}$ & FVC & FEV1 & FEV1/FVC & $\mathrm{n}$ & $\mathrm{FVC}$ & FEV1 & FEV1/FVC \\
\hline Observational & 176 & $82.29 \pm 15.06$ & $79.07 \pm 20.03$ & $95.43 \pm 16.58$ & 200 & $76.81 \pm 17.99$ & $72.57 \pm 19.40$ & $94.67 \pm 15.62$ \\
\hline Control & 107 & $87.68 \pm 14.69$ & $84.25 \pm 18.47$ & $97.09 \pm 14.73$ & 72 & $91.19 \pm 15.01$ & $87.30 \pm 13.65$ & $96.18 \pm 20.37$ \\
\hline t-test & & 2.947 & 2.172 & 1.144 & & 6.063 & 5.932 & 0.338 \\
\hline P-value & & 0.004 & 0.031 & 0.254 & & $<0.001$ & $<0.001$ & 0.734 \\
\hline
\end{tabular}

FVC, forced vital capacity; FEV1, forced expiratory volume in 1 second.

Table II. Comparison of FVC, FEV1 and FEV1/FVC in various working durations between the smoking and non-smoking subgroups.

\begin{tabular}{|c|c|c|c|c|c|c|c|c|}
\hline \multirow{2}{*}{$\begin{array}{l}\text { Working } \\
\text { age (years) }\end{array}$} & \multicolumn{4}{|c|}{ Smoking subgroup } & \multicolumn{4}{|c|}{ Non-smoking subgroup } \\
\hline & $\mathrm{n}$ & FVC & FEV1 & FEV1/FVC & $\mathrm{n}$ & FVC & FEV1 & FEV1/FVC \\
\hline$<10$ & 26 & $90.29 \pm 14.66$ & $88.42 \pm 16.64$ & $99.76 \pm 22.52$ & 10 & $89.40 \pm 14.41$ & $85.81 \pm 14.54$ & $97.67 \pm 21.44$ \\
\hline $10-20$ & 63 & $80.96 \pm 17.98^{a}$ & $76.78 \pm 16.95^{\mathrm{a}}$ & $95.82 \pm 13.23$ & 35 & $88.66 \pm 14.44$ & $84.22 \pm 11.37$ & $97.05 \pm 19.43$ \\
\hline $20-30$ & 70 & $74.16 \pm 15.60^{\mathrm{a}, \mathrm{b}}$ & $69.68 \pm 18.90^{\mathrm{a}, \mathrm{b}}$ & $93.55 \pm 16.59$ & 86 & $87.97 \pm 15.01$ & $83.34 \pm 14.70$ & $96.80 \pm 21.72$ \\
\hline$>30$ & 41 & $66.42 \pm 16.96^{\mathrm{a}-\mathrm{c}}$ & $60.97 \pm 17.15^{\mathrm{a}-\mathrm{c}}$ & $91.61 \pm 10.96$ & 45 & $85.97 \pm 14.64$ & $81.77 \pm 16.34$ & $97.12 \pm 22.72$ \\
\hline F-test & & 13.05 & 14.69 & 1.696 & & 0.125 & 0.311 & 0.011 \\
\hline P-value & & $<0.001$ & $<0.001$ & 0.169 & & 0.945 & 0.817 & 0.999 \\
\hline
\end{tabular}

FVC, forced vital capacity; FEV1, forced expiratory volume in 1 second. ${ }^{\mathrm{a}} \mathrm{P}<0.05$, vs. $<10$; ${ }^{\mathrm{b}} \mathrm{P}<0.05$, vs. $10-20$; ${ }^{\mathrm{c}}<0.05$, vs. $20-30$.

Table III. Correlation of smoking with pulmonary function in coal-mine workers with different working durations.

\begin{tabular}{lrrrr} 
& \multicolumn{2}{c}{ Smoking subgroup } & & Non-smoking subgroup \\
\cline { 2 - 4 } Index & r-value & P-value & r-value \\
\hline FVC & -0.407 & $<0.001$ & -0.069 & 0.365 \\
FEV1 & -0.426 & $<0.001$ & -0.073 & 0.338 \\
FEV1/FVC & -0.156 & 0.027 & -0.003 & 0.996 \\
\hline
\end{tabular}

FVC, forced vital capacity; FEV1, forced expiratory volume in 1 second.

Correlation of smoking with pulmonary function in coal-mine workers with different working durations. Table III demonstrates the correlation of smoking with pulmonary function in the observational group. The results indicated that FVC, FEV1 and FEV1/FVC in the smoking subgroup were negatively correlated with the time length of dust exposure (all $\mathrm{P}<0.05)$. By contrast, FVC, FEV1 and FEV1/FVC in the non-smoking subgroup of coal-mine workers were not found to be correlated with dust-exposure working duration (all $\mathrm{P}>0.05$ ).

Correlation of CTE and cumulative abnormal rate of pulmonary function. The cumulative abnormal rate of pulmonary function in the smoking subgroup increased from $0.54 \%$ (100 mg/m $\mathrm{m}^{3}$.years group) to $77.78 \%\left(1,700 \mathrm{mg} / \mathrm{m}^{3}\right.$.years group) as shown in Table IV and Fig. 3. Similarly, the cumulative abnormal rate in the non-smoking subgroup increased from $0.58 \%\left(100 \mathrm{mg} / \mathrm{m}^{3}\right.$ years group) to $75.76 \%\left(1,700 \mathrm{mg} / \mathrm{m}^{3} \cdot\right.$ years group; Table V and Fig. 3).

Correlation of smoking with pulmonary function in coal-mine workers with different CTE. CTE was positively correlated with cumulative abnormal rate of pulmonary function in both the smoking and non-smoking subgroups (smoking subgroup: $\mathrm{r}=0.884, \mathrm{P}<0.001$; non-smoking subgroup: $\mathrm{r}=0.901, \mathrm{P}<0.001)$. As shown in Table VI, FEV1 was negatively correlated with CTE in the smoking subgroup ( $r=-0.184, \mathrm{P}=0.009)$; however, FVC and FEV1/FVC showed no correlation with CTE (both $\mathrm{P}>0.05$ ). In the non-smoking subgroup, FVC, FEV1 and FEV1/FVC had no significant association with CTE (all P>0.05; Table VI). 
Table IV. Correlation of cumulative total dust exposure and cumulative abnormal rate of pulmonary function in smoking subgroup.

\begin{tabular}{|c|c|c|c|c|c|}
\hline $\begin{array}{l}\text { Cumulative total dust } \\
\text { exposure (mg/m³ years) }\end{array}$ & $\begin{array}{l}\text { Subject no. at the } \\
\text { beginning of the period }\end{array}$ & $\begin{array}{l}\text { Subject no. at the } \\
\text { end of the period }\end{array}$ & Morbidity & $\begin{array}{l}\text { Abnormal } \\
\text { rate }\end{array}$ & $\begin{array}{l}\text { Accumulative } \\
\text { abnormal rate }\end{array}$ \\
\hline 0 & 200 & 0 & 0 & 0.0000 & 0.0000 \\
\hline 100 & 200 & 7 & 1 & 0.0051 & 0.0054 \\
\hline 200 & 193 & 6 & 1 & 0.0053 & 0.0103 \\
\hline 300 & 187 & 6 & 2 & 0.0109 & 0.0161 \\
\hline 400 & 181 & 8 & 3 & 0.0169 & 0.0276 \\
\hline 500 & 173 & 10 & 4 & 0.0238 & 0.0404 \\
\hline 600 & 163 & 8 & 3 & 0.0189 & 0.0422 \\
\hline 700 & 155 & 9 & 4 & 0.0266 & 0.0449 \\
\hline 800 & 146 & 9 & 5 & 0.0353 & 0.0610 \\
\hline 900 & 137 & 14 & 7 & 0.0538 & 0.0873 \\
\hline 1,000 & 123 & 13 & 8 & 0.0687 & 0.1188 \\
\hline 1,100 & 110 & 21 & 11 & 0.1106 & 0.1716 \\
\hline 1,200 & 89 & 19 & 11 & 0.1384 & 0.2336 \\
\hline 1,300 & 70 & 23 & 12 & 0.2051 & 0.3151 \\
\hline 1,400 & 47 & 17 & 13 & 0.3377 & 0.4735 \\
\hline 1,500 & 30 & 15 & 10 & 0.4444 & 0.6320 \\
\hline 1,600 & 15 & 6 & 4 & 0.3333 & 0.6296 \\
\hline 1,700 & 9 & 9 & 3 & 0.6667 & 0.7778 \\
\hline
\end{tabular}

Table V. Correlation of cumulative total dust exposure and cumulative abnormal rate of pulmonary function in the non-smoking subgroup.

\begin{tabular}{|c|c|c|c|c|c|}
\hline $\begin{array}{l}\text { Cumulative total dust } \\
\text { exposure ( } \mathrm{mg} / \mathrm{m}^{3} \text { years) }\end{array}$ & $\begin{array}{l}\text { Subject no. at the } \\
\text { beginning of the period }\end{array}$ & $\begin{array}{l}\text { Subject no. at the } \\
\text { end of the period }\end{array}$ & Morbidity & $\begin{array}{l}\text { Abnormal } \\
\text { rate }\end{array}$ & $\begin{array}{l}\text { Accumulative } \\
\text { abnormal rate }\end{array}$ \\
\hline 0 & 176 & 0 & 0 & 0.0000 & 0.0000 \\
\hline 100 & 176 & 6 & 1 & 0.0058 & 0.0058 \\
\hline 200 & 170 & 5 & 1 & 0.0060 & 0.0117 \\
\hline 300 & 165 & 6 & 2 & 0.0123 & 0.0182 \\
\hline 400 & 159 & 7 & 2 & 0.0129 & 0.0250 \\
\hline 500 & 152 & 9 & 4 & 0.0271 & 0.0396 \\
\hline 600 & 143 & 7 & 5 & 0.0358 & 0.0620 \\
\hline 700 & 136 & 8 & 5 & 0.0379 & 0.0724 \\
\hline 800 & 128 & 7 & 5 & 0.0402 & 0.0765 \\
\hline 900 & 121 & 13 & 7 & 0.0611 & 0.0988 \\
\hline 1,000 & 108 & 11 & 8 & 0.0780 & 0.1344 \\
\hline 1,100 & 97 & 19 & 9 & 0.1029 & 0.1729 \\
\hline 1,200 & 78 & 16 & 12 & 0.1714 & 0.2567 \\
\hline 1,300 & 62 & 21 & 12 & 0.2330 & 0.3645 \\
\hline 1,400 & 41 & 15 & 10 & 0.2985 & 0.4620 \\
\hline 1,500 & 26 & 13 & 9 & 0.4615 & 0.6223 \\
\hline 1,600 & 13 & 4 & 3 & 0.2727 & 0.6084 \\
\hline 1,700 & 9 & 9 & 3 & 0.6667 & 0.7576 \\
\hline
\end{tabular}

\section{Discussion}

The present study demonstrated that the cumulative abnormal rate of pulmonary function in smoking coal-mine workers was significantly higher when compared with that in the control group, indicating that smoking is an important risk factor for the damage of pulmonary function in coal-mine workers. This may be explained by the fact that cigarette smoke contains various harmful substances, including nicotine, tobacco tar, nitrosamine and carbon monoxide, 
Table VI. Correlation of smoking with pulmonary function in coal-mine drillers with different cumulative total dust exposure.

\begin{tabular}{lcccr}
\hline & \multicolumn{2}{c}{ Smoking subgroup } & & \multicolumn{2}{c}{ Non-smoking subgroup } \\
\cline { 2 - 3 } \cline { 5 - 5 } Index & $\mathrm{r}$ & P-value & $\mathrm{r}$ & P-value \\
\hline FVC & -0.013 & 0.064 & -0.049 & 0.519 \\
FEV1 & -0.184 & 0.009 & -0.031 & 0.681 \\
FEV1/FVC & -0.083 & 0.241 & -0.035 & 0.645 \\
\hline
\end{tabular}

FVC, forced vital capacity; FEV1, forced expiratory volume in one second.

A

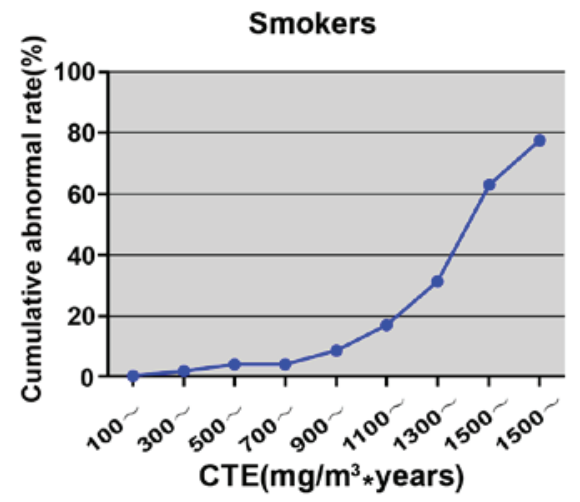

B

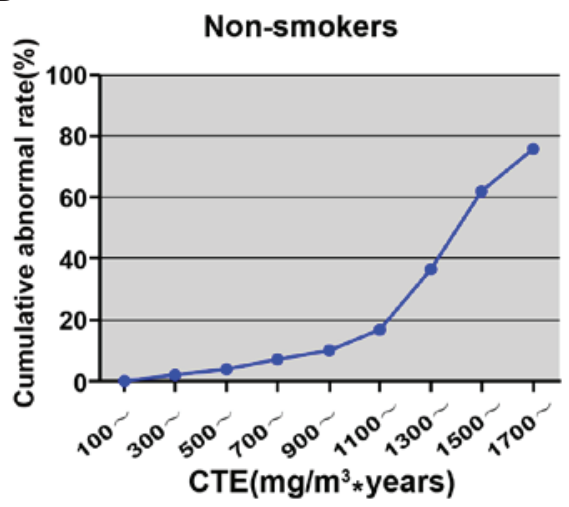

Figure 3. Correlation between CTE and cumulative abnormal rate of pulmonary function in the observational group in (A) smokers and (B) non-smokers. CTE, cumulative total dust exposure.

which causes great harm to the respiratory system (20). Inhalation of these harmful substances can activate alveolar macrophages, $\mathrm{T}$ lymphocytes and neutrophils, and these activated inflammatory cells subsequently release a variety of compounds, including leukotriene B4, interleukin-8 and tumor necrosis factor- $\alpha$ (21). These can damage the lung structure and promote the inflammatory reaction of neutral granulocyte, and lead to chronic inflammation of airway, lung parenchyma and pulmonary blood vessels (21). Furthermore, shorter and irregular bronchial epithelial cilia caused by smoking can hinder the ciliary movement, reduce local resistance, weaken phagocytosis and sterilization effects of alveolar phagocytic cells, and are able to cause bronchospasm and increase in airway resistance (22). A previous study has shown that smoking causes the increase of secretion in the airway through the sensory nerve endings, and the excessive secretion of mucus has been found to be an important risk factor of airflow obstruction (23). With the exception of airway obstruction, long-term smoking also can damage the vascular system. Carbon monoxide produced by cigarette smoking can damage the endothelial cells of the arterial wall and accelerate the development of atherosclerosis, which further decrease the gas exchange function of lungs (24). The effect of smoking on pulmonary function has been demonstrated by a previous study, and it is reported that smoking may cause a decline in pulmonary function, especially in small airway dysfunction. The combined effects of smoking and CTE on FEV1 were significantly greater than that of the smoking only and CTE only (25).
The current study indicated that FEV1 was negatively correlated with CTE in the smoking subgroup, suggesting that smoking was positively correlated with the damage of pulmonary function in coal-mine workers and CTE. Additionally, in both the smoking and non-smoking subgroups, FVC, FEV1 and FEV1/FVC were significantly lower compared with the control group, indicating that long-term exposure to coal dust significantly affected the pulmonary function of workers, with a marked decrease observed in FVC, FEV1 and FEV1/FVC. These decreased value may be due to the fact that dust inhaled through the nose or mouth can reach any part of the respiratory tract, from the nose to alveoli, and affect the entire respiratory system; similarly, respirable dust can enter the alveolar region of the lung and result in fibrosis or pneumoconiosis that may be represented by changes in FVC (26). In addition, a low FEV1/FVC value suggests the existence of airflow obstruction, while FEV1 serves an important role in classifying the severity and in following the progression of obstructive lung disease for a long time (27). Notably, a low FVC is an indicator of a restrictive disorder, and patients with a low FVC will also tends to have a low FEV1, which indicates an obstructive impairment. Generally, a healthy individual exhales approximately $70-80 \%$ of the FVC in the first second of exhalation, while people with airway obstruction exhale only $60 \%$ or less of the FVC in the first second (28).

The present study also demonstrated that FVC and FEV1 in smoking workers with a $>30$-year working duration were evidently lower when compared with those in the $<10$-year, 10-20-year and 20-30-year working duration groups. This 
suggested that with the increase of workers' exposure time to coal dust, the FVC, FEV1 and FEV1/FVC decreased more significantly, thus indicating a close association between the dust-exposure time and pulmonary function indexes in coal-mine workers. In the current study, the cumulative abnormal rate of pulmonary function increased with the increase in the amount of accumulated dust, implying that abnormal pulmonary function is directly associated with the CTE value of the worker. Therefore, a greater CTE results in a higher risk of abnormal pulmonary function. Correlation analysis demonstrated that there was a positive correlation between CTE and the cumulative abnormal rate of pulmonary function; thus, controlling the CTE of workers to a certain level range may help to control the abnormal rate of pulmonary function. Coal workers with respirable dust exposure for a long period of time are more likely to be affected by mortality from respirable diseases, indicating that the risk of mortality from respirable dust increases with the increase of respirable dust exposure (29). In agreement with the present study results, a previous study reported that CWP is primarily controlled by reducing dust exposure in coal mines with technological improvements and the establishment of dust standards (1).

In conclusion, the results of the present study indicated that smoking is an important risk factor for the damage of pulmonary function in coal-mine workers, and it is positively correlated with dust-exposure time and CTE in these individuals.

\section{References}

1. Lira M, Kohlman Rabbani E, Barkokebas Junior B and Lago E: Risk evaluation and exposure control of mineral dust containing free crystalline silica: A study case at a quarry in the Recife Metropolitan Area. Work 41 (Suppl 1): S3109-S3116, 2012.

2. Petsonk EL, Rose C and Cohen R: Coal mine dust lung disease. New lessons from old exposure. Am J Respir Crit Care Med 187: 1178-1185, 2013.

3. Ji X, Wu B, Jin K, Luo C, Han R, Chen M, Hou Z, Fan J and Ni C: MUC5B promoter polymorphisms and risk of coal workers' pneumoconiosis in a Chinese population. Mol Bio Rep 41: 4171-4176, 2014.

4. Xia Y, Liu J, Shi T, Xiang H and Bi Y: Prevalence of pneumoconiosis in Hubei, China from 2008 to 2013. Int J Environ Res Public Health 11: 8612-8621, 2014

5. Hung YP, Teng CJ, Liu CJ, Hu YW, Hung MH, Tzeng CH, Liu CY, Yeh CM, Chen TJ and Chiou TJ: Cancer risk among patients with coal workers' pneumoconiosis in Taiwan: A nationwide population-based study. Int J Cancer 134: 2910-2916, 2014.

6. Wu B, Ji X, Han R, Han L, Wang T, Yang J, Zhu B and Ni C: GITR promoter polymorphism contributes to risk of coal workers' pneumoconiosis: A case-control study from China. Immunol Lett 162: 210-216, 2014.

7. Blackley DJ, Halldin CN, Wang ML and Laney AS: Small mine size is associated with lung function abnormality and pneumoconiosis among underground coal miners in Kentucky, Virginia and West Virginia. Occup Environ Med 71: 690-694, 2014.

8. Crim C, Celli B, Edwards LD, Wouters E, Coxson HO, Tal-Singer R and Calverley PM; ECLIPSE investigators: Respiratory system impedance with impulse oscillometry in healthy and COPD subjects: ECLIPSE baseline results. Respir Med 105: 1069-1078, 2011.

9. Zuccarini G, Bocchino M, Assante LR, Rea G and Sanduzzi A Metformin/glibenclamide-related interstitial lung disease: A case report. Sarcoidosis Vasc Diffuse Lung Dis 31: 170-173, 2014.
10. van Dalen C, Harding E, Parkin J, Cheng S, Pearce N and Douwes J: Suitability of forced expiratory volume in 1 second/forced vital capacity vs percentage of predicted forced expiratory volume in 1 second for the classification of asthma severity in adolescents. Arch Pediatr Adolesc Med 162: 1169-1174, 2008.

11. Pan S, He H, Guan B, Liu T, Yuan X, Ma W and Xie Y: The effect of endoscopic sinus surgery on pulmonary function of chronic rhinosinusitis patients with asthma. Lin Chung Er Bi Yan Hou Tou Jing Wai Ke Za Zhi 28: 1118-1121, 2014.

12. Dashti HS, Shea MK, Smith CE, Tanaka T, Hruby A, Richardson K, Wang TJ, Nalls MA, Guo X, Liu Y, et al: Meta-analysis of genome-wide association studies for circulating phylloquinone concentrations. Am J Clin Nutr 100: 1462-1469, 2014.

13. Pellegrino R, Viegi G, Brusasco V, Crapo RO, Burgos F, Casaburi R, Coates A, van der Grinten CP, Gustafsson P, Hankinson J, et al: Interpretative strategies for lung function tests. Eur Respir J 26: 948-968, 2005.

14. Kallberg H, Ding B, Padyukov L, Bengtsson C, Rönnelid J, Klareskog L and Alfredsson L; EIRA Study Group: Smoking is a major preventable risk factor for rheumatoid arthritis: Estimations of risks after various exposures to cigarette smoke. Ann Rheum Dis 70: 508-511, 2011.

15. Churg A, Hall R and Bilawich A: Respiratory bronchiolitis with fibrosis-interstitial lung disease: A new form of smoking-induced interstitial lung disease. Arch Pathol Lab Med 139: 437-440, 2015.

16. M PN: World medical association publishes the revised declaration of helsinki. Natl Med J India 27: 56, 2014.

17. Jin Y: Data acquisition and processing system of pulmonary function instrument, Electronic Technology and Software Engineering, 4: 220-221, 2014 (In Chinese).

18. Mu KJ: Compiled normal values of pulmonary function nationwide. United Press of Beijing Medical University and Peking Union Medical College, 1990 (In Chinese).

19. Gooch J W: Membrane Filter Method. Springer New York, 2011 (In Chinese).

20. Talhout R, Schulz T, Florek E, van Benthem J, Wester P and Opperhuizen A: Hazardous compounds in tobacco smoke. Int J Environ Res Public Health 8: 613-628, 2011.

21. Cazzola M, Page CP, Calzetta L and Matera MG: Emerging anti-inflammatory strategies for COPD. Eur Respir J 40: 724-741, 2012.

22. Brekman A, Walters MS, Tilley AE and Crystal RG: FOXJ1 prevents cilia growth inhibition by cigarette smoke in human airway epithelium in vitro. Am J Respir Cell Mol Biol 51: 688-700, 2014.

23. Caramori G, Kirkham P, Barczyk A, Di Stefano A and Adcock I: Molecular pathogenesis of cigarette smoking-induced stable COPD. Ann N Y Acad Sci 1340: 55-64, 2015.

24. Leone A and Landini L: Vascular pathology from smoking: Look at the microcirculation! Curr Vasc Pharmacol 11: 524-530, 2013.

25. Liu X, Salter A, Thomas P, Leigh J and Wang H: Exhaled nitric oxide levels and lung function changes of underground coal miners in Newcastle, Australia. J Toxicol Environ Health A 73: 437-444, 2010.

26. Shieh TS, Chung JJ, Wang CJ, Tsai PJ, Kuo YC and Guo HR: Pulmonary function, respiratory symptoms, and dust exposures among workers engaged in early manufacturing processes of tea: A cohort study. BMC Public Health 12: 121, 2012.

27. Hancock DB, Eijgelsheim M, Wilk JB, Gharib SA, Loehr LR, Marciante KD, Franceschini N, van Durme YM, Chen TH, Barr RG, et al: Meta-analyses of genome-wide association studies identify multiple loci associated with pulmonary function. Nat Genet 42: 45-52, 2010.

28. Rao DR, Gaffin JM, Baxi SN, Sheehan WJ, Hoffman EB and Phipatanakul W: The utility of forced expiratory flow between $25 \%$ and $75 \%$ of vital capacity in predicting childhood asthma morbidity and severity. J Asthma 49: 586-592, 2012.

29. Miller BG and MacCalman L: Cause-specific mortality in British coal workers and exposure to respirable dust and quartz. Occup Environ Med 67: 270-276, 2010. 